\title{
Peripartum hysterectomy: a five year review at a tertiary care centre
}

\author{
Deepak A. V.*, K. J. Jacob, Sumi P. Maria
}

Department of Obstetrics and Gynecology, Government Medical College Hospital, Thrissur, Kerala, India

Received: 07 June 2017

Accepted: 29 June 2017

\section{*Correspondence:}

Dr. Deepak A. V.,

E-mail:drdeepakav@gmail.com

Copyright: () the author(s), publisher and licensee Medip Academy. This is an open-access article distributed under the terms of the Creative Commons Attribution Non-Commercial License, which permits unrestricted non-commercial use, distribution, and reproduction in any medium, provided the original work is properly cited.

\section{ABSTRACT}

Background: Peripartum hysterectomy is a life-saving procedure resorted to when conservative measures fail to control obstetric haemorrhage. Several predisposing factors, suboptimal care and lack of infrastructure may lead to this emergency procedure. We wanted to find out factors associated with peripartum hysterectomy and the adverse maternal outcomes at our centre.

Methods: A retrospective case series analysis of 40 cases of peripartum hysterectomy performed over a period of 5 years from January 2010 to December 2014 at Government Medical College Hospital, Thrissur, Kerala was done.

Results: The incidence of peripartum hysterectomy was $0.29 \%$. The most common indication for peripartum hysterectomy was hysterectomy was uterine atony (50\%). Thirty-five women (88\%) were between 20 and 35 years. Most of the subjects were unbooked. There were two maternal deaths (case fatality rate of 5\%) following peripartum hysterectomy during this period. All the subjects required blood transfusion.

Conclusions: Prompt performance hysterectomy before the patient's clinical condition deteriorates is the key to success. The incidence of adherent placenta is increasing, so every effort should be taken to reduce the caesarean section rates globally.

Keywords: Abnormal placentation, Atonic postpartum haemorrhage, Peripartum hysterectomy, Placenta accrete, Maternal morbidity

\section{INTRODUCTION}

Peripartum hysterectomy is an uncommon procedure in modern obstetrics, usually performed as a life-saving measure in cases of intractable obstetrical hemorrhage which fails to respond to conservative treatment. ${ }^{1,2}$ There are considerable differences in incidence in different parts of the world, depending on modern obstetric services, standards and awareness of antenatal care, obstetric expertise, blood transfusion facility and the effectiveness of family planning activities, The overall incidence is $0.05 \%$ worldwide. $^{3,4}$

Severe postpartum hemorrhage is the leading causes of maternal mortality and morbidity and represents the most challenging complication that an obstetrician will face. The main causes of the uncontrollable hemorrhage necessitating a hysterectomy have changed since the 1980s from uterine atony and rupture uterus to abnormal placentation in many studies. ${ }^{5}$

This is because of improved conservative management of uterine atony and a reduced incidence of uterine rupture due to the extensive use of the lower uterine segment incision for Caesarean section.

Abnormal placentation, which refers to both placenta previa and the morbidly adherent placenta, is thought to be increasing because of the rising Caesarean section rates. ${ }^{6}$ The present study was carried out to determine the 
associated factors, indications, type and various maternal outcomes related with peripartum hysterectomy in a tertiary care hospital.

\section{METHODS}

A retrospective study design was used. All consecutive cases of Emergency Peripartum Hysterectomy (EPH) done at the Department of Obstetrics and Gynecology, Government Medical College Hospital, Thrissur, Kerala from January 2010 to December 2014 were included in the study. These women were identified from the parturition and operation theatre registers. Their hospital notes were reviewed and the data obtained from them were recorded in a structured proforma. Maternal sociodemographic characteristics, indications for hysterectomy, type of hysterectomy, maternal outcome and complications that occurred were looked into. Women who were admitted following an EPH from elsewhere were not included in the study. The data obtained was compiled, analysed and the results were expressed in means and percentages.

\section{RESULTS}

There were 13,688 deliveries during the study period of 5 years. This included 7878 vaginal deliveries and 5810 Caesarean sections. There were 40 cases of peripartum hysterectomy during this period. Among them six (15\%) cases of EPH followed vaginal birth, and $34(85 \%)$ followed Caesarean section. The incidence of peripartum hysterectomy was 2.92 per 1000 births.

Among the subjects who underwent emergency peripartum hysterectomy, most $(78 \%)$ were referred from peripheral centres. $88 \%$ of the women were aged between 20 and 35 years. Most (88\%) of them were multiparous and $21(53 \%)$ had delivered preterm (less than 37 completed weeks of gestation) (Table 1). Among those who were referred, 8 women reached our hospital within 2 hours of referral, 12 women took 2 to 6 hours and 11 women took 6 to 12 hours to reach our centre.

Table 1: Demographic profile of women with EPH.

\begin{tabular}{|l|lll|}
\hline Characteristics & & N & $\%$ \\
\hline \multirow{3}{*}{ Booking status } & Booked in & 9 & 22 \\
\cline { 2 - 4 } & Referred (booked out) & 31 & 78 \\
\cline { 2 - 4 } & Un booked & 0 & 0 \\
\hline \multirow{3}{*}{ Age } & $<20$ & 1 & 2.5 \\
\hline \multirow{2}{*}{ Parity } & $20-35$ & 35 & 87.5 \\
\hline \multirow{2}{*}{ Gestational age } & $>35$ & 4 & 10 \\
\hline & Primipara & 5 & 12 \\
\cline { 2 - 4 } & Multipara & 35 & 88 \\
\hline & Preterm & 21 & 53 \\
\hline
\end{tabular}

Twenty-four (60\%) women who underwent EPH had a previous caesarean section. Twenty among them had one previous Caesarean section, while 4 had two prior Caesarean sections. Six (11\%) women gave history of previous uterine cavity instrumentation, which included procedures like dilatation and curettage. One woman had a history of previous myomectomy. Six women had Hypertensive disorders complicating pregnancy, while another six had gestational diabetes mellitus. Three women had multiple gestations which included two twin pregnancies and 1 triplet pregnancy (Table 2).

Table 2: Factors associated with EPH.

\begin{tabular}{|l|ll|}
\hline Risk factors & N & $\%$ \\
\hline Previous CS & 24 & 60 \\
\hline Placenta previa with adherent placenta & 15 & 37 \\
\hline Previous instrumentation & 6 & 11 \\
\hline Hypertensive disorders & 6 & 11 \\
\hline GDM & 6 & 11 \\
\hline Abruption & 4 & 8 \\
\hline Multiple pregnancy & 3 & 7.5 \\
\hline Previous myomectomy & 1 & 2 \\
\hline
\end{tabular}

Out of 34 women who had a peripartum hysterectomy following previous Caesarean section, 6 (18\%) followed elective classical CS, one was done after an elective Lower Segment Caesarean Section (LSCS) while 27 (79\%) were done following emergency LSCS. Among the other six women without previous Caesarean section, one EPH was done for a woman with a previous myomectomy and the others (five) were done in women with an unscarred uterus.

The most common indication for emergency peripartum hysterectomy was uterine atony which accounted for $50 \%$ (20) cases, followed by accrete syndromes in 37\% (15) women. In four women EPH was resorted to due to scar rupture and in one it was done for sepsis (Table 3 ).

Table 3: Indications for EPH.

\begin{tabular}{|lll|}
\hline Indication & N & $\%$ \\
\hline Uterine atony & 20 & 50 \\
\hline Accrete syndrome & 15 & 37 \\
\hline Scar rupture & 4 & 10 \\
\hline Sepsis & 1 & 3 \\
\hline
\end{tabular}

Medical and surgical conservative measures were tried sequentially in almost all cases of atonic postpartum hemorrhage (PPH) before resorting to hysterectomy. Subtotal hysterectomy was done in $24(60 \%)$ and total hysterectomy was done in $16(40 \%)$ cases. Broad spectrum antibiotic coverage was given to all women. All women required transfusion of blood and blood products. $32 \%$ women required ventilator support, $32 \%$ had postoperative pyrexia, $15 \%$ had intraoperative bladder injury, $12.5 \%$ had disseminated intravascular coagulation (DIC). 4 women required relaparotomy. The other complications included burst abdomen, paralytic ileus, pulmonary oedema and cerebellar infarct (Table 4). 
Table 4: Post-operative complications.

\begin{tabular}{|lll|}
\hline Complication & N & $\%$ \\
\hline Blood transfusions & 40 & 100 \\
\hline Ventilator & 13 & 32 \\
\hline Post op pyrexia & 13 & 32 \\
\hline Bladder injury & 6 & 15 \\
\hline DIC & 5 & 12.5 \\
\hline Relaparotomy & 4 & 10 \\
\hline Burst abdomen & 1 & 2.5 \\
\hline Paralytic ileus & 1 & 2.5 \\
\hline Cerebellar infarct & 1 & 2.5 \\
\hline Pulmonary oedema & 1 & 2.5 \\
\hline
\end{tabular}

One woman required dialysis due to acute kidney injury following PPH. The mean period of hospital stay was 10 days.

There were 2 maternal deaths (case fatality rate of $5 \%$ for $\mathrm{EPH}$ ), both due to DIC following severe postpartum hemorrhage.

\section{DISCUSSION}

The incidence of peripartum hysterectomy was 2.92 per 1000 births in our study. Our incidence of $0.29 \%$ is similar to other studies from the developing world. ${ }^{7-9}$ The incidence in previous studies ranged from 0.2 per 1000 births in the developed countries to 5.6 per 1000 births in the low and middle-income countries. ${ }^{10}$

Ours is a tertiary care centre catering to women in the districts in and around Thrissur. Most (78\%) of the women were referred to our centre from peripheral health care facilities. $11(35 \%)$ of the women who were referred from elsewhere took more than six hours to reach our facility. The distance from our centre, lack of easily available transport facilities, lack of paramedical personnel to accompany the women and financial constraints may have contributed to this. Delay in reaching a well-equipped facility may often lead to adverse and undesirable maternal and perinatal outcomes. Delay in receiving care may reduce the chances of trying conservative measures initially before resorting to hysterectomy.

Uterine atony was the most $(50 \%)$ common indication for EPH in our study. The second most common indication was the accrete syndromes. There was an increase in the incidence of morbidly adherent placenta resulting in peripartum hysterectomy over the years. While there was only 1 case of placenta accrete in 2010, the number rose to 6 in 2014. There has been significant change in the indication of emergency peripartum hysterectomy over time and from one region to another. Uterine atony used to be the most common indication for hysterectomy even in the developed world. ${ }^{11}$ Recent studies have shown that abnormal placentation is the most common indication for EPH compared to uterine atony. ${ }^{12}$ Stanco et al. reported in 1984 that $43.4 \%$ of their emergency hysterectomies were done for uterine atony, while $33.9 \%$ were due to placenta previa with accrete. A study from the same institution in 1993 stated that their primary indication was placenta accrete in $43 \%$ of the cases followed by uterine atony in $20 \%$ of the cases.

Despite advances in medicine, atonic postpartum hemorrhage still remains one of the leading causes of maternal mortality and morbidity in the developing countries. Lack of infrastructure to provide emergency obstetric care services may lead to undesirable outcomes.

The maternal mortality in our study was $5 \%$, which is comparable to a study done by Sahu et al (5.55\%). EPH was associated with intra operative and post-operative complications in over $90 \%$ of cases ranging from massive blood transfusion (2-20 units of blood and blood products), ventilator support, DIC, bladder injury and even relaparotomy. Hence early detection of untoward events, prompt and effective interventions are crucial to prevent maternal morbidity and mortality.

A detailed evaluation of all cases of EPH will help us to adopt measures to prevent or modify events leading to this emergency procedure. Women with risk factors for obstetric haemorrhage identified antenatally should be advised to seek care in a fully equipped health care facility.

Limitation of the study was this being a retrospective analysis, we could not interview these women to find out the physical and psychological impact of an unexpected hysterectomy on them and their immediate family members. The follow up recorded in their case files till their discharge from the hospital could only be obtained.

\section{CONCLUSION}

Atonic post-partum haemorrhage was the most common indication for EPH in the present study. Atonicity of the uterus can be anticipated in women with risk factors for the same. These women must therefore be advised delivery and care in a facility where adequate emergency obstetric services are available.

All women with a previous Caesarean section and diagnosed to have an anterior placenta praevia should be cared for in a tertiary centre. Unexpected life threatening obstetric hemorrhage occurring in a peripheral centre lacking adequate services should be referred to a higher centre without delay. Timely intervention can reduce the need for emergency peripartum hysterectomy. Resorting to EPH too late may also result in severe maternal morbidity and mortality. Effective antenatal care, enhancement of blood transfusion facilities and improvement in surgeon skills are a hallmark in improving outcomes. Reduction in the rate of primary Caesarean section and active management of third stage of labour will help to reduce the need for emergency peripartum hysterectomy. 


\section{ACKNOWLEDGMENTS}

Authors would like to thank Dr. Reena Raveendran Associate Professor Govt. Medical College Thrissur for her valuable suggestions and corrections.

Funding: Institutional Research Committee Government Medical College Thrissur

Conflict of interest: None declared

Ethical approval: The study was approved by the Institutional Ethics Committee

\section{REFERENCES}

1. Rossi AC, Lee RH, Chmait RH. Emergency postpartum hysterectomy for uncontrolled postpartum bleeding: a systematic review. Obstetr Gynecol. 2010;115(3):637-44.

2. Akar ES, Yilmaz BY, Yilmaz Z. "Emergency peripartum hysterectomy", European J Obstetr Gynaecol Reproduct Biol. 2004;113(2):178-81.

3. Park EH. Postpartum hemorrhage and other problems of the third stage. High Risk Pregnancy. Management options. 1999:1231-46.

4. Sakse A, Weber T, Nickelsen C, Secher NJ. Peripartum hysterectomy in Denmark 1995-2004. Acta obstetricia et gynecologica Scandinavica. 2007;86(12):1472-5.

5. Kwee A, Bots ML, Visser GH, Bruinse HW. Emergency peripartum hysterectomy: a prospective study in The Netherlands. European J Obstetr Gynecol Reproduct Biol. 2006;124(2):187-92.
6. Whiteman MK, Kuklina E, Hillis SD. "Incidence and determinants of peripartum hysterectomy" J Obstet Gynaecol. 2006;108(6):1486-92.

7. Waterstone M, Murphy JD, Bewley S, Wolfe C. Incidence and predictors of severe obstetric morbidity: case-control study Commentary: Obstetric morbidity data and the need to evaluate thromboembolic disease. Bmj. 2001;322(7294):1089-94.

8. Daskalakis G, Anastasakis E, Papantoniou N, Mesogitis S, Theodora M, Antsaklis A. Emergency obstetric hysterectomy. Acta Obstetricia et Gynecologica Scandinavica. 2007;86(2):223-7.

9. Bai SW, Lee HJ, Cho JS, Park YW, Kim SK, Park KH. Peripartum hysterectomy and associated factors. Obstetrical gynecological survey; 2003;58(7):456-7.

10. Omole-Ohonsi A, Olayinka HT. Emergency peripartum hysterectomy in a developing country. J Obstetr Gynaecol Canada. 2012;34(10):954-60.

11. Sturdee DW, Rushton DI. Caesarean and postpartum hysterectomy 1968-1983. BJOG: An Internat J Obstetr Gynaecol. 1986;93(3):270-4.

12. Zeteroglu S, Ustun Y, Engin-Ustun S, Kamasci N. "Peripartum hysterectomy in a teaching hospital in eastern region of Turkey", Europ J Obstetr Gynaecol Reproduct Biol. 2005;120(1):57-62.

Cite this article as: Deepak AV, Jacob KJ, Maria SP. Peripartum hysterectomy: a five year review at a tertiary care centre. Int J Reprod Contracept Obstet Gynecol 2017;6:3590-3. 